\title{
A Review of Surgical and Endovascular Repair of Coarctation of the Aorta
}

\author{
Siyamek Neragi-Miandoab ${ }^{1 *}$, Edward Skripochnik ${ }^{2}$, Madeleine Coleman ${ }^{1}$ and Jeffry P Schwartz ${ }^{2}$ \\ ${ }^{1}$ Department of Surgery, Division Cardiothoracic Surgery, SUNY Downstate Medical Center, USA \\ ${ }^{2}$ Department of Cardiothoracic Surgery, Loyola University Medical Center, USA
}

Submission: March 30, 2017; Published: April 07, 2017

*Corresponding author: Siyamek Neragi-Miandoab, Department of Surgery, Division Cardiothoracic Surgery, SUNY Downstate Medical Center, Brooklyn, New York, USA, Tel: 001718270 1981; Email: siyamekneragi@yahoo.com

\begin{abstract}
Coarctation of the aorta (CoAo) is a narrowing of the aorta in proximity to the ductus arteriosis that occurs in 1 of 2500 live births. It is a life-threatening condition that can present suddenly in neonates and infants. Despite great efforts, it remains one of the most difficult cardiac anomalies to diagnose prenatally. When severe, immediate surgical intervention is necessary at birth. Sometimes the condition is latent and patients are asymptomatic until childhood or adulthood. In this paper we explore the various interventions for infants and adults and discuss the stages at which surgical or endovascular techniques are recommended. Also included is a case report of a rare adult presentation of CoAo with concomitant cardiovascular disease. We discuss the possibility of treatment with 1-stage repair as well as introduce 2-stage repair as a new method for treating such patients.
\end{abstract}

\section{Introduction}

Coarctation of the aorta (CoAo) occurs in about 5-8\% of all live births with congenital heart disease (CHD), with a potentially higher incidence when including stillbirths [1,2]. The incidence is 1.7x higher in male newborns than female [3]. Although it is one of the most common congenital anomalies, prenatal screening may miss the diagnosis in $40-50 \%$ of cases [4], and further concerning is the rate of false positives of about $50 \%$ [5]. CoAo is most commonly characterized by congenital isthmic stenosis in proximity to the ductus arteriosus. A systolic gradient of greater than $20 \mathrm{mmHg}$ is highly suggestive of diagnosis [6]. Poor detection and low sensitivity of screening lead to late diagnosis and increased morbidity and mortality $[4,7]$. Depending on the severity and location of the coarctation, some patients may remain asymptomatic until adulthood, when they present with signs of heart failure, hypertension, and coronary artery disease.

\section{Etiology}

The development of CoAo remains unclear. Popular theories include familial inheritance, suboptimal fetal blood flow, and compression of the aortic arch by ductal tissue during the embryonic period [8-11]. While in utero and immediately after birth, the neonate is able to compensate for the CoAo due to the functioning fetal circulation; blood flow across the ductus arteriosus maintains adequate perfusion of the body. However, the isthmic narrowing creates a hemodynamic disturbance that leads to structural damage. As the left ventricle (LV) experiences increased pressure, there is a subsequent decrease in right-toleft flow across the foramen ovale and ductus arteriosus, leading to decompensation.

In a large study of 7,264 fetuses, antenatal suspicion of CoAo alone was found in 174 patients, of which, 62 (36\%) had CoAo confirmed by postnatal follow-up [12]. Postmortem analysis in the same study showed that 15 out of 19 either terminated pregnancies or intrauterine deaths contained CoAo. Thus, the incidence is likely higher than documented as it contributes to many unsuccessful pregnancies.[Hoffmann 1995] Moreover, CoAo is commonly a component of a other congenital defects. Head et al. [12] showed that 86 of 271 (32\%) neonates suspected to have CoAo, had the condition along with other major abnormalities such as ventricular septal defect, aortic dissection, and others. There is a high incidence (8-12\%) of CoAo in patients with Turner Syndrome (TS), the presence of which poses the greatest threat to survival $[13,14]$. In a large cohort of TS patients, CoAo was the leading cause of surgical intervention $(\mathrm{n}=12 / 17,70.5 \%)$ [15].

A severe CoAo is associated with a hypoplastic aortic arch and a prominent main pulmonary artery [3]. This condition has been reported in $25 \%-70 \%$ of cases in different studies [16] and is highly correlated with re-coarctation [16]. The abnormal pressure load created by the narrowed lumen exerts mechanical stress on the aorta proximal to the coarctation and causes 
remodeling of the vessel wall. There is a substitution of collagen for smooth muscle, which creates a stiffer, less compliant vessel [17]. The long-term consequences of vessel remodeling are increased aortic systolic pressure and systolic hypertension, both of which are diagnostic of CoAo in adults $[18,19]$. Additionally, cellular changes in this region are particularly detrimental to baroreceptors, which may play a role in the development of late hypertension. Histological studies show that over time, the CoAo causes an accumulation of dedifferentiated and apoptotic smooth muscle cells in the aortic arch $[17,20]$. A coarctation repair alone may not solve late presenting hypertension because of the permanent remodeling in the vessel wall and loss of elasticity [17].

\section{Neonatal Presentation and Treatment}

A postnatal elevation in systemic resistance leads to closure of the ductus arteroisus. In presence of an undiagnosed, severe CoAo, cardiac failure will ensue within days. Closure of the ductus leads to increased LV afterload, subsequently causing left ventricular dysfunction. Coarctation compromises lower body perfusion and causes severe acidosis due to ischemia. A prostaglandin infusion and ventilator support may become necessary as an attempt to preserve flow across the patent ductus arteriosus [3]. Early detection is crucial as ductal closure can be sudden and fatal. Despite awareness, Wren et al. [4] reported in a 20-year study that CoAo was the most undiagnosed condition of cardiac malformations, at a sobering rate of $54 \%$.

Once the diagnosis is made, surgery remains the cornerstone of the management. A brief description of the surgical techniques will follow, however in-depth analysis of the techniques is out of the scope of this manuscript. There are three surgical techniques that have been most widely used: resection with end-to-end anastomosis (EEA), left subclavian flap angioplasty (SFA), and synthetic patch aortoplasty (SPA). Even with the introduction of endovascular techniques, surgery remains the mainstay of treatment in infants less than 1-year of age [21].

\section{Adult Presentation}

Although fetal and at-birth detection is imperfect, there are far fewer patients presenting with CoAo as adults than in the postnatal period. Diagnosis in infants is crucial as infants have the highest risk of complications from CoAo. If the patient remains asymptomatic for the first year, he or she may have an uneventful life until late adulthood, when the late complications of CoAo manifest. These late complications include headaches, diminished femoral pulses, hypertension, claudication, epistaxis, and coronary artery disease [21]. Other late complications include stroke, aortic aneurysm, aortic dissection or infective endocarditis. [Turner 2007] In rare cases, patients will present with persistent chest pain, pulmonary edema, atrial fibrillation, LV hypertrophy, and valvular stenosis [22,23].

These conditions may require coronary artery bypass grafting (CABG) concurrently with coarctation repair, as well as surgical ablation therapy for atrial fibrillation and valve repair or replacement as indicated. As reported in the literature, 1-stage repair entails surgical correction of the CoAo and concomitant cardiac defects simultaneously via a median sternotomy and use of cardiopulmonary bypass [24]. In a study of 8 such cases, Bryant et al. [25] used EEA, transpericardial ascendingto-descending bypass, and elephant trunk procedure. There were no perioperative complications and survival was $100 \%$. Reents et al. [24] demonstrated 1-stage repair on 13 patients (median age 52 years) five of whom received aortic root or valve replacements concurrent with coarctation repair. Only one death was reported on 11-year follow-up, and all patients experienced cardiac improvements.

\section{Case Presentation}
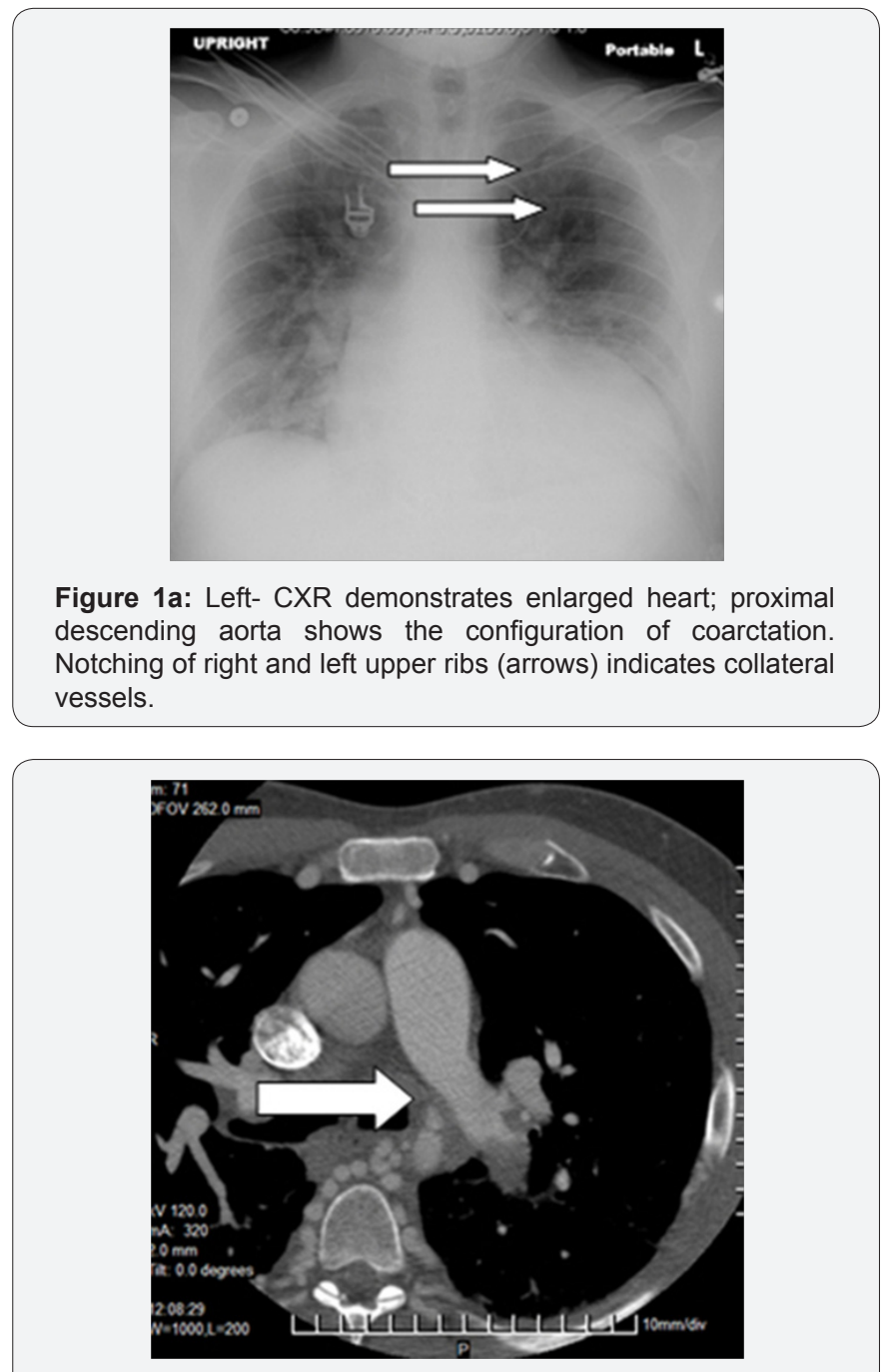

Figure 1b: CT demonstrates the cutoff of aorta at the level of coarctation.

A 37-year-old man presented to the hospital with sudden onset of chest discomfort and shortness of breath. He was found to have atrial fibrillation, and pulmonary edema. The patient had similar episodes of AFib and angina pectoris in the past, 
but had never received a cardiac catheterization. A cardiac catheterization through the femoral artery was attempted and aborted due to complete occlusion of thoracic aorta. The cardiac catheterization was completed through the brachial artery, which demonstrated severe, diffuse multi-vessel coronary artery disease and severe left ventricular hypertrophy with an ejection fraction of approximately 50\%. Further diagnostic workup during this admission revealed coarctation of the aorta (CoAo) with near complete interruption of the distal arch and proximal descending aorta on chest CT (Figure 1a). His Chest $\mathrm{X}$-ray demonstrated the usual collaterals via mammary arteries to intercostal arteries with subsequent formation of "fish ribs" (Figure 1b). Echocardiography showed left atrial enlargement and marked thickening of left ventricular walls. Given the constellation of problems including severe left ventricular hypertrophy, which makes myocardial protection difficult, the decision was made to undertake a two-stage surgical approach. The patient underwent coronary artery bypass grafting through median sternotomy followed by repair of CoAo through left lateral thoracotomy 8 weeks later.

\section{Operative Technique}

We will describe our approach in the above mentioned patient, who presented with adult CoAo. Considering this patient's condition we opted for a two stage approach. Coronary artery bypass grafting was prioritized due to his severe coronary artery disease. Following median sternotomy, inspection of the heart and aorta revealed a thin-walled ascending aorta and severe left ventricular hypertrophy. Cardiopulmonary bypass was initiated. The patient's blood pressure had an approximate 40-60 mmHg mean gradient. To avoid hypoperfusion of the kidneys and liver, the left common femoral artery was cannulated with a 20-French cannula. After aortic cross-clamping, coronary artery bypass grafting with vein grafts only was performed. The internal thoracic arteries were not useable due to the nature of patient's disease. The patient recovered from the bypass surgery rapidly and was discharged home on postoperative day 4 .

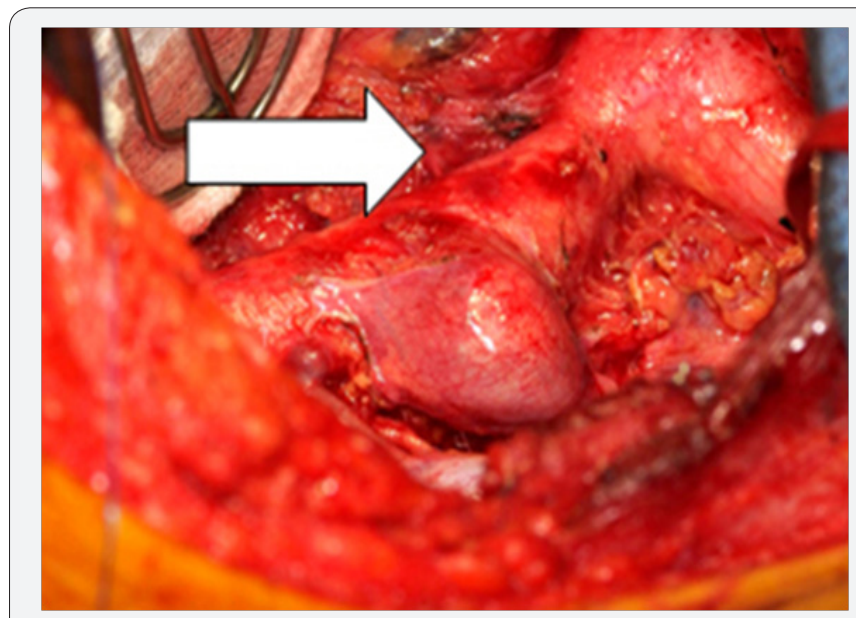

Figure 2: The coarctation, narrowing of aorta and aneurismal dilatation proximal and distal to coarctation.
Approximately eight weeks after surgical revascularization the patient returned to hospital for repair of CoAo. A spinal drain was placed preoperatively for continuous spinal drainage. The patient was placed in the right lateral decubitus position and a posterolateral thoracotomy through the fourth intercostal space was performed to expose the coarctation (Figure 2). After systemic heparinization, the left atrium was cannulated with a right angle cannula through the left superior pulmonary vein. The descending aorta was cross clamped and a 15-French catheter was inserted into the distal descending aorta beyond the cross clamp using the Seldinger technique. A partial bypass from the left atrium to distal descending aorta was initiated. No oxygenator was used and the patient's right lung was ventilated throughout the procedure. The aorta was mobilized and aortic clamps were placed proximal and distal to coarctation.

The coarctation started distal to the origin of left subclavian artery and there was an adequate sewing neck distal to the left subclavian artery. The coarctation was opened from distal to proximal, up to the takeoff of the left subclavian artery. Thrombotic material was evacuated and the bleeding intercostal arteries were suture ligated. A $22 \mathrm{~mm}$ Hemashild Dacron graft was used as an interposition graft to replace the coarctation. The distal anastomsis was performed first followed by the proximal anastomosis. The total cross-clamp time was 44 minutes; there were no perioperative or postoperative adverse events. The patient was discharged home on postoperative day 5 .

Simple coarctation repair without associated cardiac lesions, for all three surgical techniques, is achieved through a left posterolateral thoracotomy of the $4^{\text {th }}$ intercostal space. SFA involves distal division of the left subclavian artery and suturing of the remaining flap onto the resected descending aorta. Major disadvantages include, sacrifice of the left subclavian artery with subsequent decrease of left upper limb perfusion and the inadequate treatment of vessel hypoplasticity which may lead hypertension in the future. Major risks of surgical repair include lung injury, damage to phrenic or recurrent laryngeal nerves, chylothorax, and the most feared complication, paraplegia [26-29]. Maintaining a patent ductus arteriosus is crucial for perfusion of the lower body and completion of a complex arch reconstruction without use of cardiopulmonary bypass [30].

In EEA, resection begins on the inferior portion of the aortic arch and extends to the descending aorta, below the attachment of the ductus arteriosus [31]. The right innominate artery, left common carotid, and left subclavian artery all remain in place and the extent of arch resection is dependent upon the surgeon's assessment of vessel hypoplasticity. The descending aorta is then sutured to the remaining arch. It is recommended to use absorbable monofilament sutures to avoid recurrence of obstruction [32]. Variations of this fundamental technique include the end-to-side anastomosis (ESA) and the extended end-to-end anastomosis (EEEA) approaches. ESA begins with ligation of the ductus arteriosus and the isthmic narrowing. A 
proximal aortic occlusion clamp is placed over the 3 aortic arch branches and the proximal aorta.

The descending aorta is then mobilized and sutured to the proximal arch at the level of the right innominate artery and left common carotid, while the end of the aortic arch beyond the left subclavian artery is ligated [33]. EEEA is quite literally an extension of the EEA where the resection continues further proximally into the arch and distally into the descending aorta [32]. Polytetrafluoroethylene (PTFE) is used in the SPA technique. The method is fast and simple; the coarctation is incised and a patch (PTFE or homograft) is sutured into place. Similar to the SFA, this repair technique does not address hyoplasticity of the vessels and may lead to late hypertension [34].

\section{Endovascular Techniques}

With the emergence of percutaneous technology, balloon dilation became an accessible option for CoAo about 30 years ago [35]. Early results have shown that balloon dilation is equivalent to surgery. Rao et al. [36] reported a good initial response to dilation in neonates and infants; mean systolic pressure gradient decreased from $46 \mathrm{mmHg}$ to $11 \mathrm{mmHg}$. After a roughly14month follow-up however, $25 \%$ (15/60) of patients developed re-coarctation. Significantly more neonates, 5 out of 6 (86\%), experienced re-coarctation than infants, 6 out of 18 (39\%) [36]. Ten patients required re-dilation and three patients developed an aneurysm. In another study, of 80 patients treated with balloon dilation, re-coarctation occurred in $25 \%$ and aneurysm formation occurred in 13\%, after16-year follow-up [37].

With current information, we may presume that all patients, if treated as neonates or infants, would present (in the longterm) with restenosis because balloon dilation does not address the hypoplastic nature of the diseased vessel. Balloon dilation essentially causes a tear in the intima and media of the vessel wall and restenosis will occur due to the non-distensible scar tissue left over. Moreover, the tearing predisposes patients to complications such as aneurysm and aortic dissection [38]. The danger of aneurysm formation has, for the most part, deterred surgeons from using balloon dilation as the primary intervention in neonates and infants. Dilation is a feasible approach for patients initially treated surgically, who present with re-coarctation. A median follow-up of 5 years in 32 patients showed that balloon dilation after re-coarctation maintained normotension in 97\% (31/32) of patients [39].

Shortly after the development of balloon dilation, stenting was introduced as an alternative treatment option for CoAo $[40,41]$. Stenting quickly became favored over balloon dilation as it caused fewer complications [42,43]. In 153 patients followed over 15 years, Qureshi et al. [38] showed an estimated survival at 1 year and 10 years was $99 \%$ and $94 \%$ respectively. Freedom from re-intervention was $83 \%$ at 1 year, $48 \%$ at 5 years, and $45 \%$ at 10 years. Adverse events such as rupture, dissection, or aneurysm occurred in $3 \%$ of patients. In a large series review of stenting across age groups, aortic dissection occurred in 1.5\% (9/588), cerebrovascular accidents occurred in 1\% (6/588), and aneurysms (including pre-stent presentation) occurred in $2.7 \%$ (16/588) of patients [44].

\section{Comment}

Overall, all three surgical procedures carry a low mortality risk (1-3\%) $[45,46]$. As such, a more appropriate measure of success is the rate of restenosis and late hypertension. In a headto-head comparison of SPA and EEA, Walhout et al. [47] found that survival at 10 -year follow-up was $98.5 \%$ overall, concluding that both techniques, SPA and EEA, are technically successful. The standout features between the procedures were that SPA yielded higher rates of late hypertension ( $7 \%$ vs. $2 \%$ in EEA), recoarctation ( $25 \%$ vs. $14 \%$ in EAA), and aneurysm formation $(7 \%$ vs. $0 \%$ in EEA). In a different study of 201 patients, EEA showed a low in-hospital mortality rate $(2 \%)$ and a low re-intervention rate (4\%) [48]. In 188 patients under the age of 14, a comparison of SCFA, EEA, and SPA, revealed that SPA had the highest rate of re-coarctation (13\%) [49]. Aneurysm formation is more likely in SPA and left arm dysfunction is more likely in SFA [33]. Recoarctation and residual hypertension remain the most common complications and have been documented at varying degrees for each procedure [50-52]. Nevertheless, some aspects of EEA, ESA, and EEEA have made them more attractive approaches. Rubay et al. [53] suggested that EEA would be the procedure of choice in the future because it preserves the left subclavian artery, avoids use of prosthetic material, and removes more of the ductal tissue. Aggressive resection of aortic tissue that is likely hypoplastic (diameter $<1 \mathrm{~mm} / \mathrm{kg}$ ) reduces the likelihood of the common morbidities [52,54-56].

\section{Summary}

Surgery is the gold standard for congenital CoAo in neonates and infants. It boasts the lowest rates of re-coarctation and complications, while preserving a good quality of life for multiple years before need for re-intervention. Of the surgical techniques available, EEA, ESA, and EEEA are the preferred treatments as they aggressively address the hypoplastic nature often found in CoAo and prolong the time before re-coarctation. When recoarctation does arise, patients less than 1 year of age should be treated with balloon dilation. Stent implantation at this age is contraindicated because somatic growth of the aorta will lead to stent displacement, inadequacy, and several re-dilations may become necessary. If adolescent patients have not yet reached adult size, surgical intervention is the treatment of choice and balloon dilation can be used for re-coarctation repair.

However, in adolescents who have reached adult size and patients who become symptomatic in adulthood, stent placement is indicated. Operative protocol for adults who present with simultaneous CoAo and cardiovascular disease is still under review. One-stage repair has been the most frequently attempted and has received the most attention. Two-stage repair is a newly 
devised approach that treats CoAo and cardiovascular disease independently and is associated with reduced perioperative complicatrions.

\section{References}

1. Rao PS (2005) Coarctation of the aorta. Current cardiology reports $7(6): 425-434$.

2. Hoffman JI (1995) Incidence of congenital heart disease: I. Postnatal incidence. Pediatr Cardiol16(3): 103-113.

3. Rosenthal E (2005) Coarctation of the aorta from fetus to adult: curable condition or life long disease process? Heart 91(11): 1495-1502.

4. Wren C, Reinhardt Z, Khawaja K (2008) Twenty-year trends in diagnosis of life-threatening neonatal cardiovascular malformations. Arch Dis Child Fetal Neonatal Ed 93(1): F33-35.

5. Clur SA, Van Brussel PM, Ottenkamp J, Bilardo CM (2012) Prenatal diagnosis of cardiac defects: accuracy and benefit. Prenat Diagn 32(5) 450-455.

6. Egan M, Holzer RJ (2009) Comparing balloon angioplasty, stenting and surgery in the treatment of aortic coarctation. Expert Rev Cardiovasc Ther 7(11): 1401-1412.

7. Franklin O, Burch M, Manning N, Sleeman K, Gould S, et al. (2002) Prenatal diagnosis of coarctation of the aorta improves survival and reduces morbidity. Heart $87(1)$ : 67-69.

8. McBride KL, Marengo L, Canfield M, Langlois P, Fixler D, et al. (2005) Epidemiology of noncomplex left ventricular outflow tract obstruction malformations (aortic valve stenosis, coarctation of the aorta hypoplastic left heart syndrome) in Texas, 1999-2001. Birth Defects Res A Clin Mol Teratol 73(8): 555-561.

9. Loffredo CA, Chokkalingam A, Sill AM, Boughman JA, Clark EB, et al. (2004) Prevalence of congenital cardiovascular malformations among relatives of infants with hypoplastic left heart, coarctation of the aorta, and d-transposition of the great arteries. Am J Med Genet A 124A(3): 225-230.

10. Liberman L, Gersony WM, Flynn PA, Lamberti JJ, Cooper RS, et al. (2004) Effectiveness of prostaglandin E1 in relieving obstruction in coarctation of the aorta without opening the ductus arteriosus. Pediatr Cardiol 25: 49-52.

11. Hornberger LK, Sahn DJ, Kleinman CS, Copel J, Silverman NH (1994) Antenatal diagnosis of coarctation of the aorta: a multicenter experience. J Am Coll Cardiol 23(2): 417-423.

12. Head CE, Jowett VC, Sharland GK, Simpson JM (2005) Timing of presentation and postnatal outcome of infants suspected of having coarctation of the aorta during fetal life. Heart 91: 1070-1074.

13. Ho VB, Bakalov VK, Cooley M, Van PL, Hood MN, et al. (2004) Major vascular anomalies in Turner syndrome: prevalence and magnetic resonance angiographic features. Circulation 110(12): 1694-1700.

14. Ostberg JE, Brookes JA, McCarthy C, Halcox J, Conway GS (2004) A comparison of echocardiography and magnetic resonance imaging in cardiovascular screening of adults with Turner syndrome. J Clin Endocrinol Metab 89(12): 5966-5971.

15. Donadille B, Rousseau A, Zenaty D, Cabrol S, Courtillot C, et al. (2012) Cardiovascular findings and management in Turner syndrome: insights from a French cohort. Eur J Endocrinol 167(4): 517-522.

16. McElhinney DB, Clark BJ, Weinberg PM, Kenton ML, McDonald-McGinn D, et al. (2001) Association of chromosome 22q11 deletion with isolated anomalies of aortic arch laterality and branching. J Am Coll Cardiol 37(8): 2114-2149.

17. Silversides CK, Kiess M, Beauchesne L, Bradley T, Connelly M, et al (2010) Canadian Cardiovascular Society 2009 Consensus Conference on the management of adults with congenital heart disease: outflow tract obstruction, coarctation of the aorta, tetralogy of Fallot, Ebstein anomaly and Marfan's syndrome. Can J Cardiol 26: e80-97.

18. Kenny D, Cao QL, Kavinsky C, Hijazi ZM (2011) Innovative resource utilization to fashion individualized covered stents in the setting of aortic coarctation. Catheter Cardiovasc Interv 78(3): 413-418.

19. Kenny D, Polson JW, Martin RP, Wilson DG, Caputo M, et al. (2010) Surgical approach for aortic coarctation influences arterial compliance and blood pressure control. Ann Thorac Surg90(2): 600-604.

20. Lackovic V, Vukovic I (2006) Cytohistological and immunohistochemical characteristics of vascular remodelling in diseases of the blood vessels. Srpski arhiv za celokupno lekarstvo 134 Suppl 1: 9-16.

21. Peres A, Martins JD, Paramés F, Gil R, Matias C, et al. (2010) Isolated aortic coarctation: experience in 100 consecutive patients. Rev Port Cardiol 29: 23-35.

22. Morris RJ, Samuels LE, Brockman SK (1998) Total simultaneous repair of coarctation and intracardiac pathology in adult patients. Ann Thorac Surg 65: 1698-1702.

23. Thomka I, Szedo F, Arvay A (1997) Repair of coarctation of the aorta in adults with simultaneous aortic valve replacement and coronary artery bypass grafting. Thorac Cardiovasc Surg 45(2): 93-96.

24. Reents W, Froehner S, Diegeler A, Urbanski PP (2012) Ascending-todescending bypass for simultaneous surgery of aortic coarctation with other cardiac pathologies. Thorac Cardiovasc Surg 60: 210-214.

25. Bryant R, Gonzalez-Stawinski G, Pettersson GB, Svensson LG (2008) Surgical management of coarctation of the aorta in adults with concurrent cardiac and aortic disease. J Card Surg 23(6): 787-790.

26. Connolly HM, Schaff HV, Izhar U, Dearani JA, Warnes CA, et al. (2001) Posterior pericardial ascending-to-descending aortic bypass: an alternative surgical approach for complex coarctation of the aorta. Circulation 104: I133-1137.

27. Brown ML, Burkhart HM, Connolly HM, Dearani JA, Cetta F, et al. (2013) Coarctation of the aorta: lifelong surveillance is mandatory following surgical repair. J Am Coll Cardiol 62(11): 1020-1025.

28. Grinda JM, Mace L, Dervanian P, Folliguet TA, Neveux JY (1995) Bypass graft for complex forms of isthmic aortic coarctation in adults. Ann Thorac Surg 60(5): 1299-1302.

29. Diemont FF, Chemla ES, Julia PL, Sirieix D, Fabiani JN (2000) Upper limb ischemia after subclavian flap aortoplasty: unusual long-term complication. Ann Thorac Surg 69(5): 1576-1578.

30. Dave H, Rosser B, Reineke K, Nguyen-Minh S, Knirsch W, et al. (2012) Aortic arch enlargement and coarctation repair through a left thoracotomy: significance of ductal perfusion. Eur J Cardiothorac Surg 41(4): 906-912.

31. Shrivastava CP, Monro JL, Shore DF (1991) The early and long-term results of surgery for coarctation of the aorta in the $1^{\text {st }}$ year of life. European journal of cardio-thoracic 5: 61-66.

32. Gargiulo G, Pace Napoleone C, Angeli E, Oppido G (2008) Neonatal coarctation repair using extended end-to-end anastomosis. Multimed Man Cardiothorac Surg 2008(328): mmcts 2007002691.

33. Rajasinghe HA, Reddy VM, van Son JA, Black MD, McElhinney DB, et al. (1996) Coarctation repair using end-to-side anastomosis of descending aorta to proximal aortic arch. Ann Thorac Surg 61: 840-844.

34. Backer CL, Paape K, Zales VR, Weigel TJ, Mavroudis C (1995) Coarctation of the aorta. Repair with polytetrafluoroethylene patch aortoplasty. Circulation 92(9): II132-136.

35. Singer MI, Rowen M, Dorsey TJ (1982) Transluminal aortic balloon angioplasty for coarctation of the aorta in the newborn. American heart journal 103(1): 131-132. 
36. Rao PS, Galal O, Smith PA, Wilson AD (1996) Five- to nine-year followup results of balloon angioplasty of native aortic coarctation in infants and children. J Am Coll Cardiol 27: 462-470.

37. Ergül Y, Nişli K, Dindar A, Eker Ömeroğlu R, Aydoğan U (2011) The comparison a 16-year follow-up results of balloon angioplasty for aortic coarctation in children of different age groups: a single-center experience. Anadolu Kardiyol Derg 11: 336-342.

38. Qureshi AM, McElhinney DB, Lock JE, Landzberg MJ, Lang P, et al. (2007) Acute and intermediate outcomes, and evaluation of injury to the aortic wall, as based on 15 years experience of implanting stents to treat aortic coarctation. Cardiol Young 17(3): 307-318.

39. Siblini G, Rao PS, Nouri S, Ferdman B, Jureidini SB, et al. (1998) Longterm follow-up results of balloon angioplasty of postoperative aortic recoarctation. Am J Cardiol 81: 61-67.

40. O'Laughlin MP, Perry SB, LockJE, Mullins CE (1991) Use of endovascular stents in congenital heart disease. Circulation 83: 1923-1939.

41. Morrow WR, Smith VC, Ehler WJ, VanDellen AF, Mullins CE (1994) Balloon angioplasty with stent implantation in experimental coarctation of the aorta. Circulation 89: 2677-2683.

42. Suarez WA, Kurczynski TW, Bove EL (1999) An unusual type of combined aortic coarctation due to fibromuscular dysplasia. Cardiol Young 9: 323-326.

43. Gewillig M, Budts W, Boshoff D, Maleux G (2012) Percutaneous interventions of the aorta. Future cardiology 8: 251-269.

44. Golden AB, Hellenbrand WE (2007) Coarctation of the aorta: stenting in children and adults. Catheter Cardiovasc Interv 69: 289-299.

45. Hager A, Schreiber C, Nutzl S, Hess J (2009) Mortality and restenosis rate of surgical coarctation repair in infancy: a study of 191 patients. Cardiology 112: 36-41.

46. Sakurai T, Stickley J, Stumper O (2012) Repair of isolated aortic coarctation over two decades: impact of surgical approach and associated arch hypoplasia. Interactive cardiovascular and thoracic surgery 15(5): 865-870.

47. Walhout RJ, Lekkerkerker JC, Oron GH, Hitchcock FJ, Meijboom EJ, et al. (2003) Comparison of polytetrafluoroethylene patch aortoplasty and end-to-end anastomosis for coarctation of the aorta. J Thorac Cardiovasc Surg 126(2): 521-528.

48. Kaushal S, Backer CL, Patel JN (2009) Coarctation of the aorta: midterm outcomes of resection with extended end-to-end anastomosis. Ann Thorac Surg 88: 1932-1938.

49. Dehaki MG, Ghavidel AA, Givtaj N, Omrani G, Salehi S (2010) Recurrence rate of different techniques for repair of coarctation of aorta: A 10 years experience. Annals of Pediatr Cardiol 3: 123-126.

50. Backer CL, Mavroudis C, Zias EA, Amin Z, Weigel TJ (1998) Repair of coarctation with resection and extended end-to-end anastomosis. Ann Thorac Surg 66(4):1365-1370.

51. Cohen M, Fuster V, Steele PM, Driscoll D, McGoon DC (1989) Coarctation of the aorta. Long-term follow-up and prediction of outcome after surgical correction. Circulation 80: 840-845.

52. Wood AE, Javadpour H, Duff D, Oslizlok P, Walsh K (2004) Is extended arch aortoplasty the operation of choice for infant aortic coarctation? Results of 15 years' experience in 181 patients. Ann Thorac Surg 77: 1353-1357.

53. Rubay JE, Sluysmans T, Alexandrescu V (1992) Surgical repair of coarctation of the aorta in infants under one year of age. Long-term results in 146 patients comparing subclavian flap angioplasty and modified end-to-end anastomosis. J Cardiovasc Surg (Torino) 33(2): 216-222.

54. Cobanoglu A, Thyagarajan GK, Dobbs JL (1998) Surgery for coarctation of the aorta in infants younger than 3 months: end-to-end repair versus subclavian flap angioplasty: is either operation better? Eur J Cardiothorac Surg 14(1): 19-25.

55. O’Sullivan JJ, Derrick G, Darnell R (2002) Prevalence of hypertension in children after early repair of coarctation of the aorta: a cohort study using casual and 24 hour blood pressure measurement. Heart 88(2): 163-166.

56. Ou P, Bonnet D, Auriacombe L, Pedroni E, Balleux F, et al. (2004) Late systemic hypertension and aortic arch geometry after successful repair of coarctation of the aorta. Eur Heart J 25(20): 1853-1859.

\section{Your next submission with Juniper Publishers will reach you the below assets}

- Quality Editorial service

- Swift Peer Review

- Reprints availability

- E-prints Service

- Manuscript Podcast for convenient understanding

- Global attainment for your research

- Manuscript accessibility in different formats

( Pdf, E-pub, Full Text, Audio)

- Unceasing customer service

Track the below URL for one-step submission https://juniperpublishers.com/online-submission.php 